\title{
Dynamic Decision Making in ELT Classroom
}

\author{
${ }^{1}$ S. A.Manga Tayaru, ${ }^{2}$ D.Vijaya Lakshmi \\ ${ }^{1}$ Assistant Professor, Shri Vishnu Engineering College for Women, Bhimavaram, A.P. \\ ${ }^{2}$ Sr. Assistant Professor, Vishnu Institute of Technology, Bhimavaram, A.P. India
}

\begin{abstract}
English is the most popular and utilitarian language in the world. English is the link language as India is developed with multilingual and multicultural country. Nowadays innovative teaching practices are taking place in education. English is playing a pivotal role in the life of every student from KG to $P G$. In this context teacher's role is exceptionally important. Teachers' role will not be completed in the classroom and it will be continued outside of it also. Teacher plays different roles in the classroom among them, dynamic decision making plays a key role. Characteristics of teacher, types of decision making, decision making in evaluation, dynamic decision making and effective classroom management are to be discussed in dynamic decision making.
\end{abstract}

Keywords: Decision, evaluation, student, teacher.

\section{Introduction}

English is the most popular and utilitarian language in the world. English is the link language as India is developed with multilingual and multicultural country. Nowadays innovative teaching practices are taking place in education. English is playing a pivotal role in the life of every student from KG to PG. In this context teacher's role is exceptionally important. Teachers' role will not be completed in the classroom and it will be continued outside of it also. Teacher plays different roles in the classroom among them dynamic decision making plays a key role.

\section{Characteristics of a Teacher}

A good teacher possesses a very good command over the subject knowledge, introduces modern techniques / methods of teaching, explains concepts well and illustrates them with real time examples, guides students and monitors progress of the students, is confident and motivating, encourages and fascinates with her/his attitude, prepares and plans well for each class, builds up a good rapport with the students, builds up students' confidence, is a role model for students, pace the class well, encourages the students to interact with one another in the language labs and discussion classes, learns from the students, applies interpersonal skills, pays attention towards dull students, runs the class with fun teaching, corrects the mistakes of the students by giving the feedback.

\section{Types of Decision Making}

Teacher makes regularly ample decisions in the classroom. Decision making in the classroom is pertaining not only to the classroom but also outside of it. Teachers make decisions in the classroom regarding methodology, material, instructional techniques and assessment procedure. Before going to discuss dynamic decision making teaching activities should be discussed. Firstly, planning activity- in this activity teachers' concentration always will be on objectives and outcomes of the classroom. Secondly implementing activitywhatever teachers have designed to teach to the students, which should be the implementing activity especially for plan of action. Lastly, managing activity- teacher's attention will be not only on lesson plan and its implementation but also on managing the class. Dynamic decision making is indispensable skill for a teacher along with thinking. Teacher usually confronts three types of decision making while the class is going on. They are reflective decisions, immediate decisions and routine decisions.

a) Reflective decisions are taken by the teacher especially outside the classroom. Before teacher handles the class he/she can go through the given syllabus and they decide and plan for an action in the class or prepare a lesson plan for that individual class or semester action plan. Now-a-days in all engineering colleges teachers are asked to submit their action plans and lesson plans before the commencement of the class work. Syllabus will be decided by the university but all the teachers in the department gather to discuss syllabus content, activity based teaching and assessment parameters. Teacher's obligation is to implement the plan prepared by him/her in the classroom and reflections are required.

b) Immediate decisions are on the spot decisions which are taken by the teacher in the classroom. These decisions are made within the dynamics of the classroom situation whereas reflective decisions are made 
outside the classroom. To create a good ambiance to the students in the classroom teacher takes the immediate decisions, for instance, controlling the classroom, resolve the disputes, changing the topic based on the requirement of the students, introducing an article in the classroom from newspaper based on the clarification of the doubt of the student.

c) Routine decisions are automatic decisions taken by the teacher in the classroom. These types of decisions are default decision in the classroom and teacher adapts a part of his/her teaching style. For example students are coming to the language labs to participate in different activities throughout the semester. Teacher handles the class smoothly, dividing them into different groups for discussions, managing the noise, providing the feedback based on the parameters set by the university/department.

All the activities and decisions come into two different phases like preactive phase and interactive phase. Planning activity and reflective decision making come under preactive phase whereas, implementing activity and managing activity and immediate decisions and routine decisions come under interactive phases. For better understanding the types of decisions, it is given in the form of the flow chart.

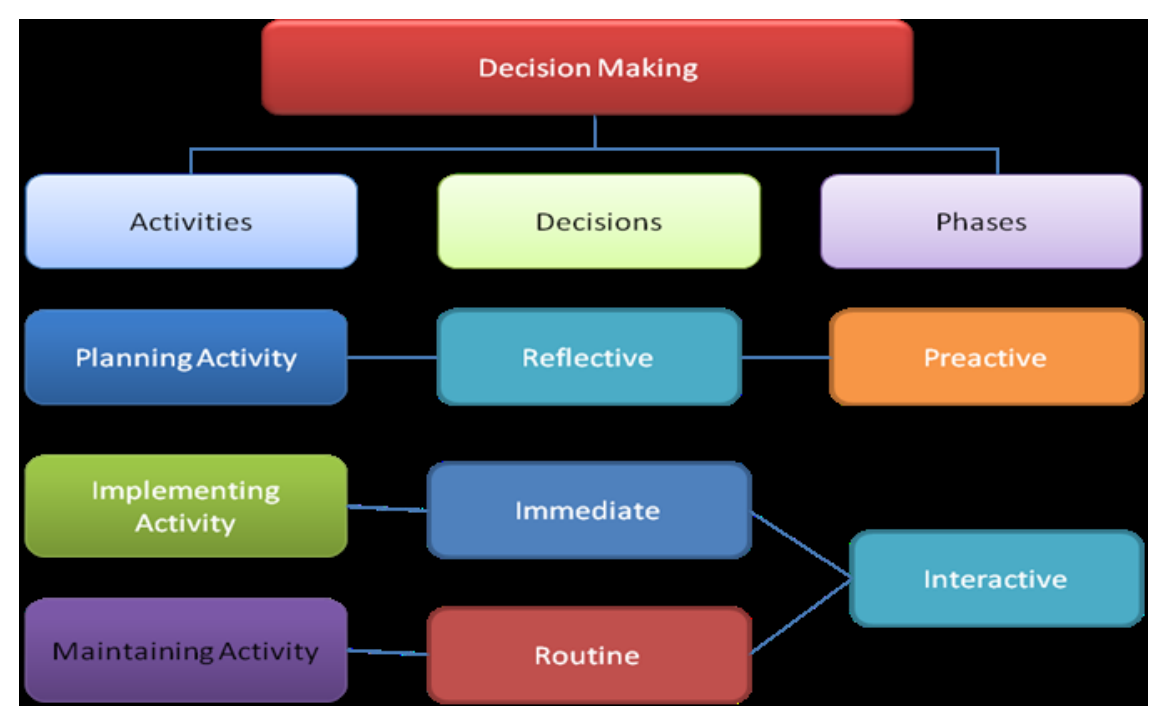

\section{Classroom Decision Making}

In classroom decision making there is a degree of correspondence between both the activities and decisions. They are of three types-planning decisions, interactive decision and evaluate decisions. Before the class starts planning decisions play a role in reaching the objectives and organizing the idea of teaching. While the teacher is implementing the lesson plan and achieving the objectives the interactive decision takes place. This type of decision is a spot decision. After completion of the class, evaluate decision comes into action. Summing up the topic or the thorough understanding of the topic leads to recap and reiterate the lesson plan. It paves the way for the next topic as it is the connecting link between the earlier topic and next topic. Handouts are provided to the students after this session and ask them to complete the given task. A sample handout to evaluate the performance of the students in the classroom:

\begin{tabular}{|l|l|}
\hline Performance of the teacher & Decision concerned \\
\hline Topic selection & \\
\hline Discussions about the syllabus & \\
\hline Recap of the selected topic & \\
\hline Providing handouts & \\
\hline Implementing the activity & \\
\hline Explaining the rules & \\
\hline Selecting the material & \\
\hline
\end{tabular}

\section{Dynamic Decision Making and Effective Classroom Management:}

For dynamic decision making and effective classroom management, teacher should possess the managerial qualities and strategies in handling the class. Teacher has to take micro decisions and macro decisions throughout the class like motivating the students to learn the topic, controlling the class and maintain the discipline are the two essential things to meet leaning objectives in the class, facilitating to achieve the goal of learning. Teacher is isolated in the class in making decisions. No management, colleagues and students will be there when the teacher is organizing the class. So she/he is the sole leader of the class. Teacher considers 
characteristics of the students, their needs, circumstances and motivation. Methodology, using of materials are on the other hand.

Teachers' decisions represent their reflections, beliefs and personalities. Teacher should acquire his/her own style of teaching. Role of a teacher and student will be known through three different stages-presentation stage, practice stage and production stage. When the teacher gives the information and explanation to the students the presentation stage takes place. When the student is given an opportunity to practice what the teacher has taught in the class is the second stage i.e. practice stage and the third stage is production stage which takes place when the teacher gives chance to produce the language after receiving the information. At the same time the role of the student is to understand what the teacher has presented at the presentation stage. Manoeuvre the use of language at the practice stage and produce language at the producing stage. The role of the teacher in such stages is control, monitor and facilitates in the classroom.

\section{Conclusion}

Teachers are making decisions about the curriculum designed by the university. Always teachers' concentration will be there on teaching and organizing the content, methodology to use, essential and unessential things and evaluation procedures. The classroom decision is about the presentation of the material or content, explanation of the selected topic, coverage of the content from the curriculum, solving the doubts and settling the disputes. At the end teacher decides the assessment parameters through the students' progress and information to the parents. Teachers make many a decision throughout the day in the classroom and outside the classroom from the trivial to complex. Teachers prove that they are the dynamic decision makers in presenting their judgements, interpersonal and intrapersonal skills and leadership style.

\section{References}

[1]. Calderhead, James. 1984. Teacher' Classroom Decision Making. London: Holt Rinehart and Winston.

[2]. CAPE Alumni Internet Connection. Teacher as Decision Makers: Grammar Teachers As Decision Makers, Sandra Lee McKay.English Teacher Talk. (2009). Viewed on $20^{\text {th }}$ October 2013. Retrieved from http://www.cape.edu/docs/TTalk0036.pdf

[3]. Parrot, Martin.1993. Tasks for Language Teacher Training. Cambridge: Cambridge University Press.

[4]. Richards, Jack C and Lockhart, Charles. 1994. Reflective Teaching in Second Language Classrooms. Cambridge University Press. 